\title{
Hydrochlorofluorocarbon and hydrofluorocarbon emissions in East Asia determined by inverse modeling
}

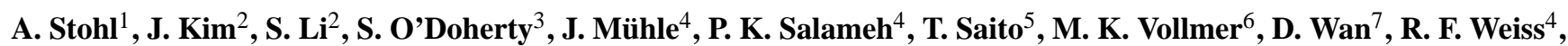 \\ B. Yao ${ }^{8}$, Y. Yokouchi ${ }^{5}$, and L. X. Zhou ${ }^{8}$ \\ ${ }^{1}$ Norwegian Institute for Air Research, Kjeller, Norway \\ ${ }^{2}$ School of Earth and Environmental Sciences, Seoul National University, Seoul, Korea \\ ${ }^{3}$ School of Chemistry, University of Bristol, Bristol, UK \\ ${ }^{4}$ Scripps Institution of Oceanography, University of California, San Diego, California, USA \\ ${ }^{5}$ National Institute for Environmental Studies, Tsukuba, Japan \\ ${ }^{6}$ Swiss Federal Laboratories for Materials Testing and Research (Empa), Duebendorf, Switzerland \\ ${ }^{7}$ State Key Joint Laboratory for Environmental Simulation and Pollution Control, Peking University, Beijing, China \\ ${ }^{8}$ Centre for Atmosphere Watch and Services, Key Laboratory for Atmospheric Chemistry, Chinese Academy of \\ Meteorological Sciences, Beijing, China
}

Received: 18 November 2009 - Published in Atmos. Chem. Phys. Discuss.: 1 February 2010

Revised: 3 April 2010 - Accepted: 13 April 2010 - Published: 16 April 2010

\begin{abstract}
The emissions of three hydrochlorofluorocarbons, HCFC-22 $\left(\mathrm{CHClF}_{2}\right)$, HCFC-141b $\left(\mathrm{CH}_{3} \mathrm{CCl}_{2} \mathrm{~F}\right)$ and HCFC$142 \mathrm{~b}\left(\mathrm{CH}_{3} \mathrm{CClF}_{2}\right)$ and three hydrofluorocarbons, HFC-23 $\left(\mathrm{CHF}_{3}\right), \mathrm{HFC}-134 \mathrm{a}\left(\mathrm{CH}_{2} \mathrm{FCF}_{3}\right)$ and HFC-152a $\left(\mathrm{CH}_{3} \mathrm{CHF}_{2}\right)$ from four East Asian countries and the Taiwan region for the year 2008 are determined by inverse modeling. The inverse modeling is based on in-situ measurements of these halocarbons at the Japanese stations Cape Ochi-ishi and Hateruma, the Chinese station Shangdianzi and the South Korean station Gosan. For every station and every $3 \mathrm{~h}, 20$-day backward calculations were made with the Lagrangian particle dispersion model FLEXPART. The model output, the measurement data, bottom-up emission information and corresponding uncertainties were fed into an inversion algorithm to determine the regional emission fluxes. The model captures the observed variation of halocarbon mixing ratios very well for the two Japanese stations but has difficulties explaining the large observed variability at Shangdianzi, which is partly caused by small-scale transport from Beijing that is not adequately captured by the model. Based on HFC- 23 measurements, the inversion algorithm could successfully identify the locations of factories known to produce HCFC-22 and emit HFC-23 as an unintentional byproduct. This lends substantial credibility to the inversion method. We report national emissions for China, North Korea, South Korea and
\end{abstract}

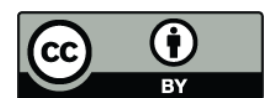

Correspondence to: A. Stohl (ast@nilu.no)
Japan, as well as emissions for the Taiwan region. Halocarbon emissions in China are much larger than the emissions in the other countries together and contribute a substantial fraction to the global emissions. Our estimates of Chinese emissions for the year 2008 are $65.3 \pm 6.6 \mathrm{kt} / \mathrm{yr}$ for HCFC-22 (17\% of global emissions extrapolated from Montzka et al., 2009), $12.1 \pm 1.6 \mathrm{kt} / \mathrm{yr}$ for HCFC-141b (22\%), $7.3 \pm 0.7 \mathrm{kt} / \mathrm{yr}$ for HCFC-142b (17\%), $6.2 \pm 0.7 \mathrm{kt} / \mathrm{yr}$ for HFC-23 (>50\%), $12.9 \pm 1.7 \mathrm{kt} / \mathrm{yr}$ for HFC-134a (9\% of global emissions estimated from Velders et al., 2009) and $3.4 \pm 0.5 \mathrm{kt} / \mathrm{yr}$ for HFC$152 \mathrm{a}(7 \%)$.

\section{Introduction}

The emissions of chlorofluorocarbons (CFCs) and halons have decreased substantially over the last decade and will decrease further as a result of the phaseout of their production and use required by the Montreal Protocol. The Montreal Protocol allows CFCs to be replaced by hydrochlorofluorocarbons (HCFCs) as transitional substitutes. HCFCs are now also being phased out globally over the next decade but emissions in some developing (Article 5) countries are still growing and, thus, HCFC abundances in the atmosphere are increasing (Montzka et al., 2009). HCFCs are also being replaced now by hydrofluorocarbons (HFCs), which do not deplete ozone but - as other halocarbons - are powerful greenhouse gases. Without regulation, HFC emissions may

Published by Copernicus Publications on behalf of the European Geosciences Union. 
increase so strongly during the next decades that their contribution to the radiative forcing of the climate system could be equivalent to $9-19 \%$ of the carbon dioxide emissions by the year 2050 (Velders et al., 2009). Therefore, HFCs have come into the focus of international climate policy (Molina et al., 2009) and emission estimates using both bottom-up approaches based on economic data (e.g., McCulloch et al., 2003; Ashford et al., 2004; Velders et al., 2009) and topdown methods based on atmospheric measurements are required.

On a global scale, emissions can be determined from measured atmospheric concentrations using simple box models (Montzka et al., 2009) or three-dimensional models (Hartley and Prinn, 1993; Prinn et al., 2000). On a regional scale, emissions can be derived from the ratio between observed halocarbon concentrations and concentrations of a substance with known emission fluxes (often carbon monoxide), or by inverse modeling. Both methods have been used frequently for inferring halocarbon emissions in North America, Europe or Australia (Manning et al., 2003; Dunse et al., 2005; Millet et al., 2009; O'Doherty et al., 2009). One region of great interest is East Asia because of its recent rapid economic development.

In East Asia, relatively good bottom-up information is available for Japan (PRTR, 2009; GIO, 2009) which, however, is not the largest halocarbon source in East Asia. According to official reports to the United Nations Environment Programme (UNEP, 2009), China alone now accounts for nearly $50 \%$ of the global HCFC consumption. Unfortunately, no official Chinese emission estimates are available and deriving emissions from the consumption data requires knowledge on the various HCFC banks. For some halocarbons, however, bottom-up emission information for China has recently become available. Wan et al. (2009) provide estimates of CFC, halon, HCFC-22 and HCFC-141b emissions. Their data reveals large growth rates of Chinese HCFC-22 emissions, for instance $27 \%$ between the years 2005 and 2006. In another study $\mathrm{Hu}$ et al. (2009) report HFC-134a emissions from automobile air conditioners in China and project a tripling of emissions from 2005 to 2010 and another doubling until 2015.

A number of studies have reported on halocarbon measurements in or downwind of China. Blake et al. (2003) and Palmer et al. (2003) calculated CFC emissions from China based on downwind aircraft measurement data but their studies did not include HCFCs or HFCs. Barletta et al. (2006) reported halocarbon (including HCFC) concentrations in Chinese cities but did not determine emissions. Similarly, Chan et al. (2006) found strong halocarbon sources in the Pearl River Delta but did not explicitly report source strengths. Guo et al. (2009) also analyzed halocarbon data from the Pearl River Delta and identified the major source types (e.g., solvent use, refrigeration, etc.) but did not derive source strengths. To our knowledge, until this year, only Yokouchi et al. (2006) estimated HCFC and HFC emissions for China, based on measurements made at an island downwind of China. In a recent inversion study, Stohl et al. (2009) found HCFC-22 emissions for China for the year 2006 of $71 \mathrm{kt} / \mathrm{yr}$, which is in reasonable agreement with the bottomup estimate of $58 \mathrm{kt} / \mathrm{yr}$ from Wan et al. (2009) for the same year. In another inversion study, Vollmer et al. (2009) calculated much higher Chinese HCFC-22 emissions for the year 2007, 165 (140-213) kt/yr, which cannot be explained by the emission growth between the two years. Thus, there is presently large uncertainty in the emissions of HCFCs and HFCs from China. While for Japan, top-down estimates are also available (Yokouchi et al., 2005; Stohl et al., 2009), for the Taiwan region, South Korea and North Korea, there exists even less information than for China. This motivated the present study which uses measurement data from several stations in East Asia, an atmospheric transport model and an inversion algorithm to compute HCFC and HFC emissions for several countries in East Asia (mainland China including Hong Kong and Macao abbreviated as "China" in the following, North Korea, South Korea, Japan) as well as the Taiwan region.

\section{Methods}

\subsection{Measurement data}

We use in-situ measurements of HCFCs and HFCs performed at four stations in East Asia during the year 2008 (Table 1). Two of these stations, Hateruma and Cape Ochiishi, are operated by the National Institute for Environmental Studies in Japan (Yokouchi et al., 2006). The Gosan station is operated by the Seoul National University, Korea (Kim et al., 2010). The Shangdianzi measurement system is jointly operated by the Chinese Academy of Meteorological Sciences of the China Meteorological Administration and the Swiss Federal Laboratories for Materials Testing and Research (Vollmer et al., 2009). Hateruma is a small $\left(12.5 \mathrm{~km}^{2}\right.$ ) island at the southern end of the Japanese Archipelago, Cape Ochi-ishi is a nature preserve located at the eastern coast of Hokkaido, Gosan is located near the southwestern tip of Jeju Island located south of the Korean Peninsula, and Shangdianzi is located in a mountainous area approximately $100 \mathrm{~km}$ northeast of Beijing in the North China Plain (see Table 1 and Fig. 1 for station locations). All four stations are situated in unpolluted surroundings but Shangdianzi receives frequent transport from Beijing and, thus, often records very high halocarbon mixing ratios. We also use data from the AGAGE (Advanced Global Atmospheric Gases Experiment; Prinn et al., 2000) measurement stations Mace Head (Ireland) and Trinidad Head (USA) to better constrain emissions in Europe and North America. The inversion results for East Asia are only marginally sensitive to including data from these stations. 
Table 1. List of the measurement stations, their coordinates, the operating institutions, the period and the species for which data were available.

\begin{tabular}{lccrcrc}
\hline Station & Latitude & Longitude & Altitude $(\mathrm{m})$ & Institution & Period & Measured species \\
\hline Cape Ochi-ishi, Japan & 43.2 & 145.5 & 96 & NIES & $1 / 2008-12 / 2008$ & HCFC-22, HCFC-141b, HCFC-142b, HFC-23, HFC-134a, HFC-152a \\
Shangdianzi, China & 40.7 & 117.1 & 294 & CMA/EMPA & $1 / 2008-12 / 2008$ & HCFC-22, HCFC-142b \\
Gosan, South Korea & 33.3 & 126.2 & 72 & SNU & $1 / 2008-12 / 2008$ & HCFC-22, HCFC-141b, HCFC-142b, HFC-23 HFC-134a, HFC-152a \\
Hateruma, Japan & 24.0 & 123.8 & 47 & NIES & $1 / 2008-12 / 2008$ & HCFC-22, HCFC-141b, HCFC-142b, HFC-23, HFC-134a, HFC-152a \\
Mace Head, Ireland & 53.3 & -9.9 & 25 & AGAGE & $1 / 2008-9 / 2008$ & HCFC-22, HCFC-141b, HCFC-142b, HFC-134a, HFC-152a \\
Trinidad Head, California & 41.0 & -124.1 & 140 & AGAGE & $1 / 2008-9 / 2008$ & HCFC-22, HCFC-141b, HCFC-142b, HFC-134a, HFC-152a \\
\hline
\end{tabular}

At Shangdianzi, a gas chromatograph with dual electron capture detector is operated and HCFC-22 and HCFC$142 \mathrm{~b}$ are detected using an ambient temperature trapping system and oxygen-doping techniques (Vollmer et al., 2009). All other stations use automated low-temperature preconcentration units coupled with gas chromatograph/mass spectrometer (GC/MS) measurement techniques. At the Gosan station, "Medusa-GC/MS" technology is used (Miller et al., 2008), and at the Japanese stations, a measurement technique developed at NIES is used (Yokouchi et al., 2006), all allowing for the fast (every 1-2h) measurements of a suite of halogenated substances. For all stations except the Japanese stations, the measurements are reported on the AGAGE SIO-2005 primary calibration scale (for HFC-23, on the SIO-2007 scale), whereas for the Japanese stations the NIES scale was used. Intercomparisons between the NIES and the AGAGE SIO standards performed at Hateruma during the year 2008 yielded ratios of $0.987,1.006,0.999,0.995$, 1.010 and 1.003 for, respectively, HCFC-22, HCFC-141b, HCFC-142b, HFC-23, HFC-134a and HFC-152a. These ratios are so close to 1 that maximum errors in the inverted emissions due to these differences are less than $1 \%$ for all substances. This is much less than other errors, so that no effort was made to put all the data on the same scale. Most of the stations measure the major HCFCs and HFCs; however, at Shangdianzi, only HCFC-22 and HCFC-142b are measured (Table 1).

\subsection{Inversion method}

The inversion procedure is based on 20-day backward simulations with the Lagrangian particle dispersion model FLEXPART (Stohl et al., 1998, 2005) (see http://transport.nilu.no/ flexpart). FLEXPART is a stochastic model with detailed treatment of turbulence and convection and uses meteorological analyses at $1^{\circ} \times 1^{\circ}$ resolution from the European Centre for Medium-Range Weather Forecasts. The FLEXPART output is an emission sensitivity which can be ingested directly by the inversion algorithm. Multiplying the footprint emission sensitivity with the emission flux from either the a priori or the a posteriori inventory gives the simulated mixing ratio at the receptor, which can be compared with the measurements. We do not describe the model simulations in more detail here, as the model setup was identical to the one used by Stohl et al. (2009).

Figure 1 shows a map of the emission sensitivity averaged over all model calculations for all stations and for the entire year. There is high sensitivity to emissions over Japan, North and South Korea, the Taiwan region, Mongolia and most of China. Emissions in other parts of Asia, especially India, are not well constrained by the available measurements.

The inversion method is based on work by Seibert (2000) and improvements by Eckhardt et al. (2008) and Stohl et al. (2009). The version used here is exactly the same as described and evaluated by Stohl et al. (2009) where all the mathematical details can be found. The basic idea is to find the emission distribution which leads to the best fit between the measurements and the model results. "Best" agreement is measured as the sum of the squared errors inversely weighted with the uncertainty variances. We also identify "outliers" and assign them large uncertainties to avoid that the solution is strongly influenced by large measurement and/or model errors (for more details, see Stohl et al., 2009).

If there were sufficient observation data, this would be enough to obtain a solution to our problem. However, not all regions are well constrained by the observations. This could render the solution unstable, even if the number of observations exceeds the number of unknown emission values, leaving us with a so-called ill-conditioned inverse problem. To prevent this, we add a priori knowledge on the emission distribution and the emission uncertainty (see subsection 2.3). In the so-called cost function measuring the observation-model misfit, this adds a second term that measures the deviation of the solution from the a priori emissions and is inversely weighted by the assumed emission uncertainties. Minimizing this cost function yields a linear system of equations that can be solved analytically with standard linear algebra methods. The solution optimizes the agreement between the model and the observations while at the same time minimizing the deviation from the a priori emissions. Finally, negative emissions which can occur in the solution are removed in an iterative scheme where the uncertainty of the concerned emissions is decreased step by step, therefore binding them more closely to zero. The inversion is performed for a variable-resolution emission grid. Emission grid boxes in the vicinity of the stations have a maximum 


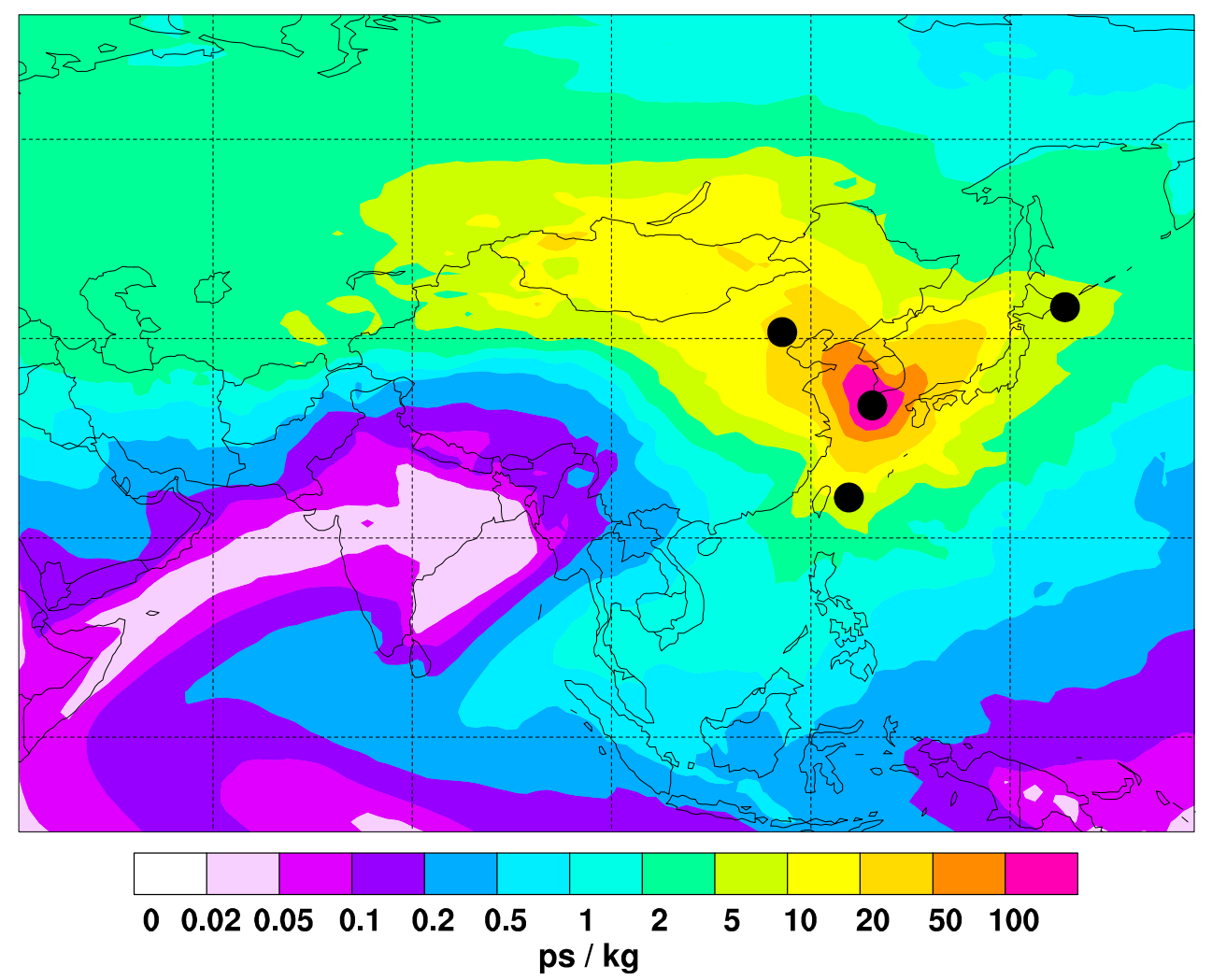

Fig. 1. Footprint emission sensitivity in picoseconds per kilogram obtained from FLEXPART 20 d backward calculations averaged over all model calculations for all stations and for the entire year 2008. Measurement sites are marked with black dots.

resolution of $1^{\circ} \times 1^{\circ}$, whereas further away the resolution is lower.

Since HCFCs and HFCs are long-lived substances with lifetimes much longer than the 20 days of the model simulations, the model can only capture enhancements over a socalled baseline, which results from "older" emissions. The enhancements convey most of the information on regional emissions, so extending the model simulations further back in time would only marginally improve the emission estimates. The baseline must be subtracted from the measurements before the model-measurement comparison and is estimated by the algorithm as part of the inversion problem. Our total number of observations for HCFC-22 is 11706, we optimize the emissions in 1377 boxes, and we determine monthly baseline values for every station. The number of observations is roughly eight times the number of unknowns.

\subsection{A priori emissions}

We employed several sources of information to define our a priori emissions for the HCFCs. First, Montzka et al. (2009) determined global emissions based on a large number of measurements taken at several sites and a simple box model. They reported emissions until the year 2007, which we extrapolated to 2008 by assuming a linear trend. For HCFC-
22, HCFC-141b and HCFC-142b we thus obtained values of, respectively, 375, 55 and $44 \mathrm{kt}$ for the year 2008. For China, Wan et al. (2009) reported HCFC-22 and HCFC-141b emissions of 79.3 and $12.1 \mathrm{kt}$, respectively, for the year 2008 . For Japan, HCFC-22 and HCFC-142b emissions in the year 2007 were reported as 7.6 and $0.69 \mathrm{kt}$, respectively (PRTR, 2009). These data were used directly. The Japanese inventory (PRTR, 2009) also lists HCFC-141b emissions but these were found to be unrealistically high in a comparison with recent aircraft measurement data (Yokouchi, unpublished data) and test inversions confirmed that, so we decided to not use these data. For all other countries, only lumped HCFC (i.e., not individual HCFC) consumption (not emission) data were available for the year 2007 from the United Nations Environment Programme (UNEP, 2009). The year 2008 global emissions for individual HCFC species (minus emissions in China and Japan) were, thus, disaggregated to countries according to the UNEP 2007 total HCFC consumption data. For HCFC-142b for China and for HCFC-141b for Japan, consumption data were used, too, since no emission data were available. Substituting emission by consumption data will likely lead to underestimated a priori emissions in countries with decreasing consumption and overestimated emissions in countries with increasing consumption because of the lagged 
release of banked halocarbons. However, these errors should be small enough to be corrected by the inversion. Within the countries, the emissions were distributed according to population taken from CIESIN (2005). The Taiwan region is a special case since it is not a signatory of the Montreal Proto$\mathrm{col}$ and does not report consumption to UNEP. We assumed emissions of 3, 1, and $0.03 \mathrm{kt} / \mathrm{yr}$ for HCFC-22, HCFC-141b and HCFC-142b, respectively, which are extrapolations of consumption values reported by Tsai and Chou (2008) for the years 1996-2005.

For HFC-134a and HFC-152a, we used decadal global bottom-up emission projections from Velders et al. (2009). Linear interpolation between the years 2000 and 2010 yielded 2008 emissions of $144 \mathrm{kt} / \mathrm{yr}$ for HFC-134a and $51 \mathrm{kt} / \mathrm{yr}$ for HFC-152a. These values can be compared to the older projections for 2008 from Ashford et al. (2004) of $180 \mathrm{kt} / \mathrm{yr}$ and $27 \mathrm{kt} / \mathrm{yr}$, respectively. In our previous study (Stohl et al., 2009) we have shown that for the years 20052006 the HFC-152a projections of Ashford et al. (2004) were too low. For the spatial distribution of the emissions, we used total emissions for the year 2007 for countries where such information was available through the United Nations Framework Convention on Climate Change (UNFCCC, see http://unfccc.int). For the Taiwan region, we assume emissions of 3.2 and $0.17 \mathrm{kt} / \mathrm{yr}$ for HFC-134a and HFC-152a, respectively, rough extrapolations of potential emissions reported by Tsai (2006) for the years 1998-2004. All other emissions and emissions within the countries were disaggregated according to population.

$\mathrm{Hu}$ et al. (2009) recently estimated HFC-134a emissions from automobile air conditioners in China. For their base case, emissions were $7.3 \mathrm{kt} / \mathrm{yr}$ in 2005 and $21.2 \mathrm{kt} / \mathrm{yr}$ in 2010 which, assuming a constant growth rate of about $23 \% / \mathrm{yr}$ for the period in between, gives an emission of $13.6 \mathrm{kt}$ for the year 2008. Not included in this estimate are emissions due to the import of foreign cars and other uses of HFC-134a, which we subjectively assume is roughly a third of the total emission thus estimated at $20.3 \mathrm{kt} / \mathrm{yr}$. For HFC-152a, no estimates for China are available. Since the default a priori for China $(8.4 \mathrm{kt} / \mathrm{yr})$ is very high, we subjectively adjust the Chinese emission to $4 \mathrm{kt} / \mathrm{yr}$.

For HFC-23 we use the EDGAR version 4.0 emission inventory for the year 2005 (European Commission, 2009) because no more actual a priori information was available. The global emissions in this inventory are $12 \mathrm{kt} / \mathrm{yr}$, in good agreement with the current best practice projection of McCulloch et al. (2007) and a value of $13.5 \mathrm{kt} / \mathrm{yr}$ derived from measurement data by Montzka et al. (2010) for the period 20062008. China accounts for more than two thirds of EDGAR's global HFC-23 emissions. The reason we have not used the EDGAR inventory for the other species is that the emission distribution often is unrealistic (e.g., no emissions in China).

The emissions are all determined on a global $1^{\circ} \times 1^{\circ}$ grid. For the inversion, individual grid boxes are combined in regions of low emission sensitivity but the original $1^{\circ} \times$ $1^{\circ}$ resolution is kept near the measurement sites (Stohl et al., 2009). We assume that all the a priori emission fluxes have an uncertainty of 50\%. To allow the inversion algorithm to make reasonably large adjustments even in grid cells with small (or zero) a priori emissions, we prescribe a minimum uncertainty of at least $100 \%$ of the global mean emission flux. The emissions over the oceans are set to zero. All a posteriori emissions are remapped onto the $1^{\circ} \times 1^{\circ}$ grid, using population distribution within coarser inversion boxes.

\subsection{Uncertainties}

In section 3, we show error statistics and emission flux maps from our "reference" inversion, which uses the best available a priori information and data from all stations. We quantify the uncertainty of the results by performing sets of 18 inversions for every substance. First, we remove the additional a priori emission information on China and Japan from Wan et al. (2009), Hu et al. (2009) and PRTR (2009) and instead assign these countries emissions proportional to their fraction of reported consumption (for HCFCs) or population (for HFCs). For both this and the reference emission scenario, we reduce and increase all emissions by $50 \%$ and repeat the inversions. Finally, we repeat these six inversions with measurement data either from Gosan or from Hateruma removed. Table 2 provides a summary of these 18 inversions. For reporting national emissions, our reference inversion should yield the best estimate but we also report the mean of all inversions, and we characterize uncertainty by the standard deviation of all inversions performed. The standard deviations characterize the uncertainties only within the applied inversion system. Additional errors may arise from systematic errors in the dispersion model or the meteorological input data and these errors may also be influenced by the station network geometry. For instance, boundary layer heights may be systematically over- or underestimated, which would generate emission errors of a comparable relative magnitude as those of the boundary layer heights. Errors are also made in the attribution of emissions to a specific country, which is problematic especially for smaller countries. For instance, large emissions are concentrated at the border between North and South Korea (Fig. 3), which makes it difficult to split the emissions between these two countries. Therefore, we caution that the true uncertainties of our estimates are higher than the standard deviations reported, especially for the smaller countries North Korea, South Korea and the Taiwan region.

\section{Results}

\subsection{Timeseries}

HCFC-22 is the most abundant of the hydrochlorofluorocarbons measured in the atmosphere and has a lifetime of about 

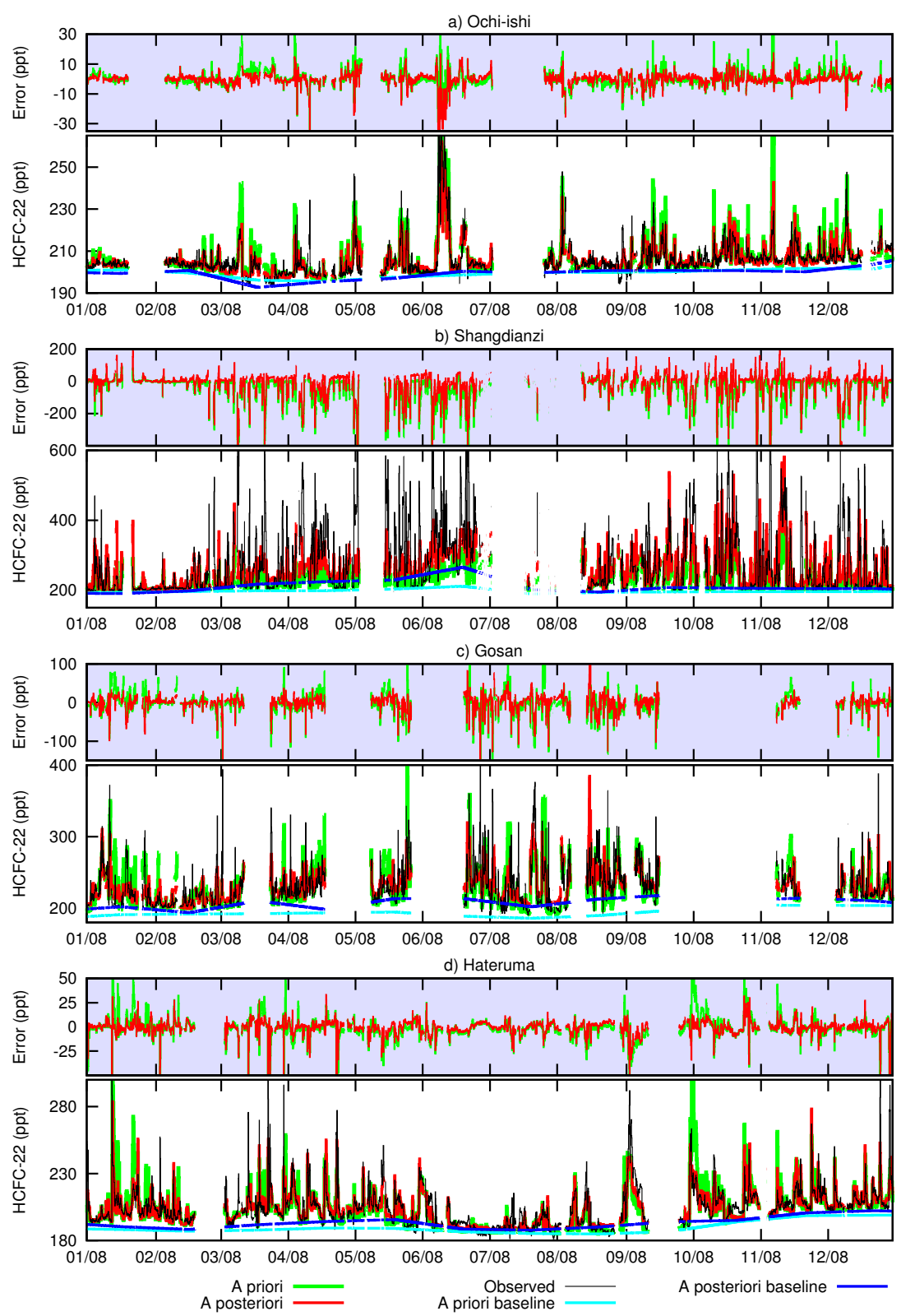

Fig. 2. HCFC-22 time series for (a) Ochi-ishi, (b) Shangdianzi, (c) Gosan, and (d) Hateruma. For every station, the lower panels show the observed (black lines) as well as the modeled mixing ratios using the a priori emissions (green lines) and the a posteriori emissions (red lines), the a priori baseline (cyan lines), and the a posteriori baseline (blue lines). The upper panels show the model errors based on the a priori emissions (green lines) and the a posteriori emissions (red lines).

$12 \mathrm{yr}$ (O'Doherty et al., 2004). It is used mainly in domestic refrigeration but also as a foam-blowing agent and for the production of fluoropolymers (McCulloch et al., 2006). It is also the substance with the most complete record in our measurement data set. Figure 2 shows timeseries of the measured and simulated HCFC-22 mixing ratios and the corresponding errors for all measurement sites. Model results are shown for both the a priori and the a posteriori emissions from our reference inversion, using the best available bottom-up emis- sion information and the entire measurement data set. The Ochi-ishi station is the most remote site where typical enhancements over the baseline during pollution episodes are only $20 \mathrm{ppt}$, an order of magnitude less than at Shangdianzi, the most polluted site. The model is able to capture most of the pollution episodes at Ochi-ishi very well, resulting in squared Pearson correlation coefficients between the 3 -hourly measured and simulated mixing ratios of $r_{a}^{2}=0.63$ and $r_{b}^{2}=0.70$ when using the a priori and the a posteriori 
Table 2. Ensemble of 18 inversions used to quantify the uncertainty of the a posteriori emissions. "China/Japan" indicates whether the special information available for these countries was used ("Y"), or not ("N"). "Scaling" indicates how reference emissions have been scaled, and "Station removed" indicates which data set has been removed from the inversion.

\begin{tabular}{rrrc}
\hline Inversion number & China/Japan & Scaling & Station removed \\
\hline 1 & $\mathrm{Y}$ & $100 \%$ & - \\
2 & $\mathrm{~N}$ & $100 \%$ & - \\
3 & $\mathrm{Y}$ & $50 \%$ & - \\
4 & $\mathrm{~N}$ & $50 \%$ & - \\
5 & $\mathrm{Y}$ & $150 \%$ & - \\
6 & $\mathrm{~N}$ & $150 \%$ & - \\
7 & $\mathrm{Y}$ & $100 \%$ & Gosan \\
8 & $\mathrm{~N}$ & $100 \%$ & Gosan \\
9 & $\mathrm{Y}$ & $50 \%$ & Gosan \\
10 & $\mathrm{~N}$ & $50 \%$ & Gosan \\
11 & $\mathrm{Y}$ & $150 \%$ & Gosan \\
12 & $\mathrm{~N}$ & $150 \%$ & Gosan \\
13 & $\mathrm{Y}$ & $100 \%$ & Hateruma \\
14 & $\mathrm{~N}$ & $100 \%$ & Hateruma \\
15 & $\mathrm{Y}$ & $50 \%$ & Hateruma \\
16 & $\mathrm{~N}$ & $50 \%$ & Hateruma \\
17 & $\mathrm{Y}$ & $150 \%$ & Hateruma \\
18 & $\mathrm{~N}$ & $150 \%$ & Hateruma \\
\hline
\end{tabular}

emissions, respectively (Table 3 ). The successful modeling can be attributed to the fact that the HCFC-22 variability at Ochi-ishi is driven mainly by long-range transport events, which FLEXPART can simulate very well using the emission inventory and the ECMWF meteorological data, which are both used at a resolution of $1^{\circ} \times 1^{\circ}$. Good correlation, especially for the a posteriori results $\left(r_{a}^{2}=0.43, r_{b}^{2}=0.63\right)$, is also found for Hateruma, whereas lower values are obtained for Gosan $\left(r_{a}^{2}=0.25, r_{b}^{2}=0.44\right)$ and Shangdianzi $\left(r_{a}^{2}=0.19\right.$, $r_{b}^{2}=0.26$ ). The low correlations for Shangdianzi are due to its proximity to Beijing. The frequent small-scale transport events producing spikes in the observed HCFC-22 mixing ratios cannot be captured with the $1^{\circ} \times 1^{\circ} \mathrm{ECMWF}$ data and emission grid. Consequently, the standard deviation of the a posteriori simulated mixing ratio (52 ppt) underestimates the observed variability (103 ppt) by a factor two.

The inversion reduces the root-mean-square (RMS) errors from the a priori to the a posteriori simulation by $15-27 \%$ (Table 3). The error reductions are moderate because the mixing ratios simulated with FLEXPART using the reference a priori emissions have relatively small biases compared to the observations (Fig. 2). Simulations using other a priori emission scenarios yield much larger a priori RMS errors which are indeed reduced strongly by the inversion. For instance, our high emission scenario without information on Chinese emissions from Wan et al. (2009) yields for the Ochi-ishi station an a priori RMS error of $9.3 \mathrm{ppt}$, which the inversion reduces by $50 \%$. This proves that the relatively small error reductions reported in Table 3 are not due to binding the a posteriori emissions too tight to their a priori values. Instead, our reference a priori HCFC-22 emissions are relatively close to reality and require only moderate adjustments in most regions. We do not show time series for the other halocarbons but the model performance using a posteriori emissions was similar for all of them.

\subsection{Emission patterns}

Figure 3 shows maps of the a priori and a posteriori emissions of HCFC-22. The a priori distribution (Fig. 3a) is relatively smooth because national bottom-up numbers were disaggregated according to population. The highest emission flux densities are found in South Korea because of its high reported HCFC consumption but large fluxes occur all over East Asia. The a posteriori distribution (Fig. 3b) is considerably less homogeneous, with high emissions often concentrated in small regions or even in single grid cells. These emission hot spots often coincide with large cities. For instance, the highest a posteriori flux densities are associated with Beijing, Shanghai and cities along the lower reaches of the Yellow River (e.g., Zhengzhou). On the other hand, emissions in South Korea and in rural areas of China are substantially reduced compared to the a priori inventory, best seen in a difference plot between the a posteriori and the a priori emissions (Fig. 3c). Also marked in Fig. 3b, c are the locations of Chinese and Japanese factories known to have produced HCFC-22 during the year 2008, information which is not used in the inversion. Notice that most but not all Chinese factories are shown on the map because of incomplete information available to us. While loss during manufacture is only one source of HCFC-22, most of the factory locations, especially in China, are associated with high a posteriori emissions and large emission increases by the inversion. The only exception is the westernmost cluster of factories located in Sichuan province, likely because its influence on the measurements is masked by other strong but closer sources.

HFC-23 is a halocarbon with a very long (246 yr) lifetime and correspondingly large global warming potential (McCulloch et al., 2007). HFC-23 is an unintentional byproduct of HCFC-22 manufacture (McCulloch et al., 2007) but also has a few minor applications (e.g., in fire extinguishing equipment and as a low-temperature refrigerant). Thus, HFC-23 originates mainly from the few and mostly known factories. HFC-23 emissions can be reduced substantially by process optimization and thermal oxidation of the vent gases and, consequently, current emissions in developed countries are relatively low. A few of the Chinese factories have recently adopted this technology in the framework of the Clean Development Mechanism but in 2005 more than two thirds of the global HFC-23 emissions of $12 \mathrm{kt} / \mathrm{yr}$ occurred in China, according to the EDGAR inventory. By analyzing data from Hateruma, Yokouchi et al. (2006) reported Chinese HFC-23 emissions of $10 \pm 5 \mathrm{kt} / \mathrm{yr}$ for the years 2004/2005. At Gosan, 
a) A priori emissions

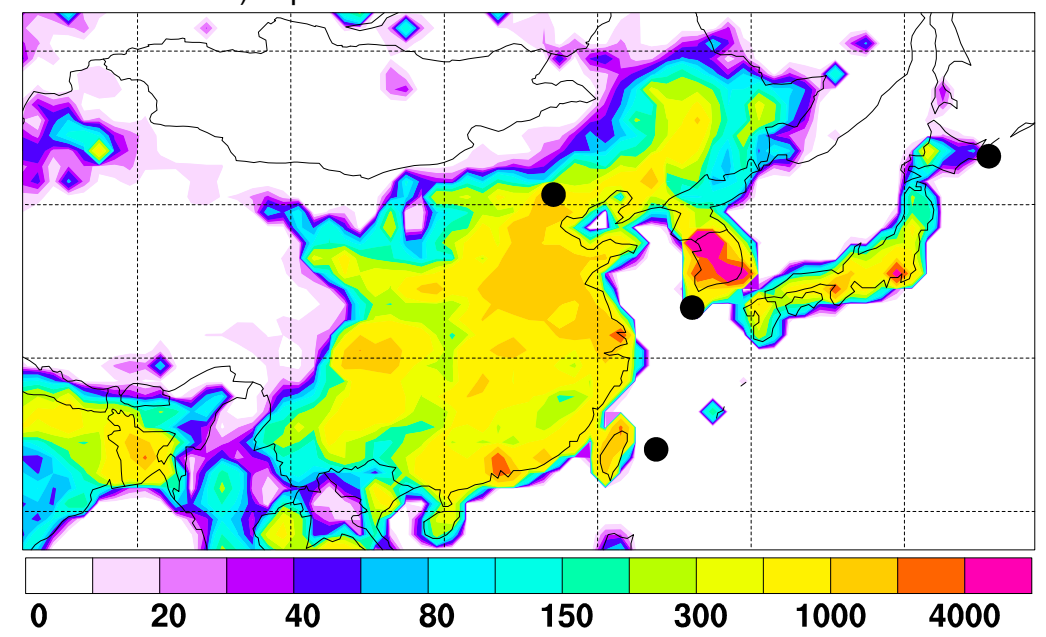

b) A posteriori emissions

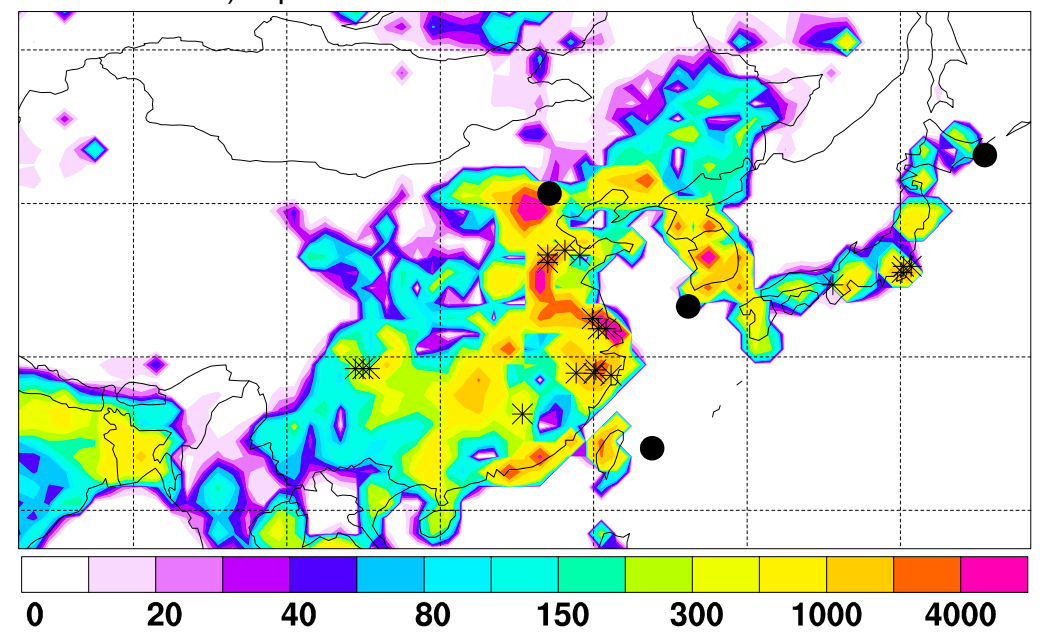

c) A posteriori minus a priori emissions

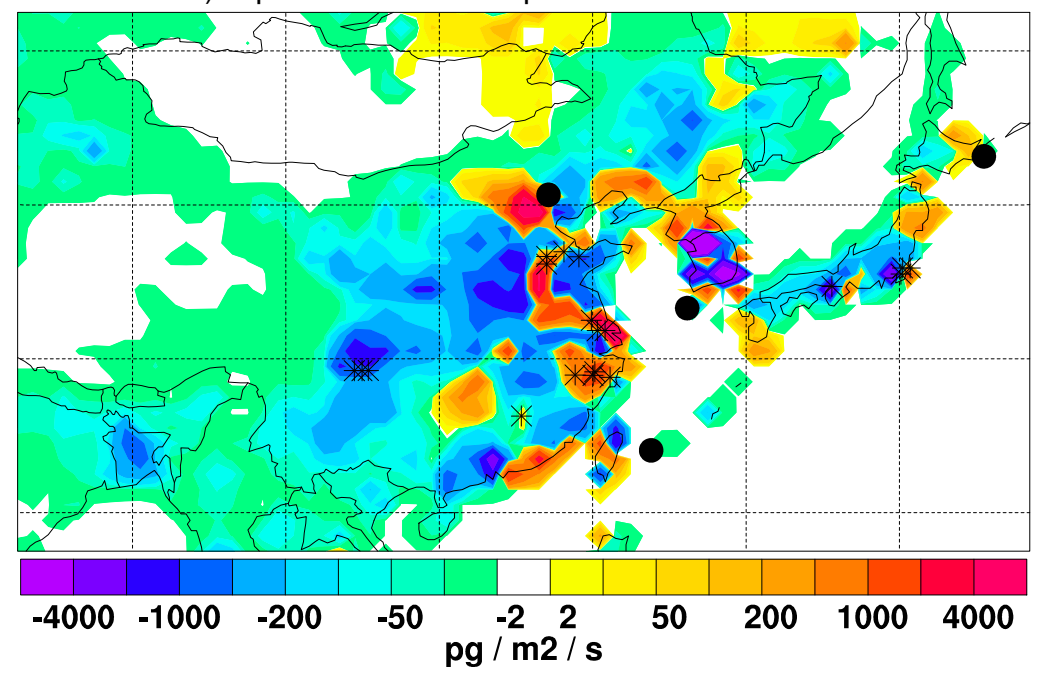

Fig. 3. Maps of the a priori (a), a posteriori (b), and difference between a posteriori and a priori (c) HCFC-22 emissions in picogram per square meter and second for the year 2008. Black dots indicate the location of measurement stations, asterisks in panels (b) and (c) mark the locations of Chinese and Japanese factories known to have produced HCFC-22 in the year 2008. This information was not used in the inversion. 
Table 3. Error characteristics for HCFC-22 by station. $E^{a}$ and $E^{b}$ denote the a priori and, respectively, a posteriori RMS errors for the full data set, including outliers, $1-E^{b} / E^{a}$ is the relative error reduction. $E_{n}^{b}$ is the a posteriori error normalized with the standard deviation of the observed mixing ratios. $N$ denotes the number of observations. $r_{a}^{2}$ and $r_{b}^{2}$ are the squared Pearson correlation coefficients between the observations and the a priori and, respectively, a posteriori model results.

\begin{tabular}{lrrrrrrr}
\hline Station & $E^{a}$ & $E^{b}$ & $1-E^{b} / E^{a}$ & $E_{n}^{b}$ & $N$ & $r_{a}^{2}$ & $r_{b}^{2}$ \\
& $\mathrm{ppt}$ & $\mathrm{ppt}$ & $\%$ & $\%$ & & & \\
\hline Cape Ochi-ishi & 5.7 & 4.6 & 19.0 & 54.9 & 2320 & 0.63 & 0.70 \\
Shangdianzi & 107.0 & 91.5 & 14.5 & 88.5 & 2241 & 0.19 & 0.26 \\
Gosan & 28.7 & 22.1 & 22.8 & 74.9 & 1626 & 0.25 & 0.44 \\
Hateruma & 12.9 & 9.5 & 26.8 & 61.5 & 2531 & 0.43 & 0.63 \\
\hline
\end{tabular}

HFC-23 concentrations are still enhanced when the air arrives from China (Kim et al., 2010), suggesting continued HFC-23 emissions in China. Despite the point-source nature of the bulk of the HFC-23 emissions, the EDGAR a priori emission field is very smooth and follows the population distribution (Fig. 4a), which is unrealistic. This makes HFC23 a good test case for our inversion method, as it can be evaluated whether the locations of the known HCFC-22 production plants can be retrieved. Derived emission strengths for these factories cannot be validated, however, because no HFC-23 emission data are publicly available.

The inversion reduces the a priori HFC- 23 emissions in most of China but increases emissions strongly in a few isolated areas (Fig. 4c). The highest increases occur in the Shandong, Jiangsu, Zhejiang and Sichuan provinces, indeed coinciding with the locations of known HCFC-22 factory clusters. Also in Japan, the strongest emission increase occurs where three factories are located near $140^{\circ} \mathrm{E}$, even though total HFC-23 by-product emissions in Japan are reported to be only $18.6 \mathrm{t} / \mathrm{yr}$ (GIO, 2009). The fact that emissions are increased in the vicinity of nearly all known plants lends substantial credibility to our calculations. Strong increases also occur in Beijing, probably indicating some intentional use of HFC-23 there. The a posteriori emission map (Fig. 4b) shows a few other maxima relatively far away from the measurement stations that are more difficult to explain. Use of HFC-23 may occur in these areas, or there may be HCFC22 factories that are unknown to us. It is also possible that some of the maxima are artifacts as the measurement stations will rarely receive a signal from these distant areas without contamination by closer sources.

Emission maps for the other halocarbons are not shown since the patterns are all relatively similar to those of HCFC22 (Fig. 3). However, differences will be described in section 3.4.

\subsection{Robustness of the inversion}

Next, we explore how robust our inversion results are against changes in the set of stations used for the inversion, discussed at the example of total HCFC-22 emissions in China.
Our reference HCFC-22 inversion results in a total emission from China of $65 \mathrm{kt} / \mathrm{yr}$. Keeping the reference a priori emissions but removing one station at a time yields Chinese emissions of 66,63 , and $61 \mathrm{kt} / \mathrm{yr}$, respectively, without Gosan, Hateruma and Shangdianzi. This indicates a remarkable robustness of the inversion results. Single-station inversions yield more variable results: 83, 77, 64 and $125 \mathrm{kt} / \mathrm{yr}$ for Gosan, Hateruma, Ochi-ishi and Shangdianzi. The results for the first three stations are relatively close to either the reference a priori or a posteriori emissions whereas the Shangdianzi-only value is much higher. However, the a posteriori RMS error for Shangdianzi is not reduced much by the higher emissions: from $91 \mathrm{ppt}$ for our reference inversion (Table 3) to $88 \mathrm{ppt}$ for the single-station inversion. Thus, the Shangdianzi data are compatible with a large range of Chinese total emissions in the model. Geographically, the emission differences between the two inversions are largest southeast of Beijing. Emissions from this region are transported to Shangdianzi via Beijing and their signal is overwhelmed by the closer Beijing emissions. This demonstrates the importance for a successful inversion of using data from several stations that "observe" the same emission regions from different viewing angles.

Using data from Shangdianzi, Vollmer et al. (2009) reported much higher Chinese HCFC-22 emissions of $165 \mathrm{kt} / \mathrm{yr}$ for the year 2007. They upscaled results obtained for a limited inversion domain containing about $40 \%$ of China's population to all of China by assuming that the per capita emissions are the same both in the limited domain and in all of China. However, this assumption is not valid. In our reference inversion, the per capita emissions are increased in Beijing but decreased in the mostly rural areas of China outside their domain (compare Fig. $3 \mathrm{c}$ and Fig. 2 in Vollmer et al., 2009). 
a) A priori emissions

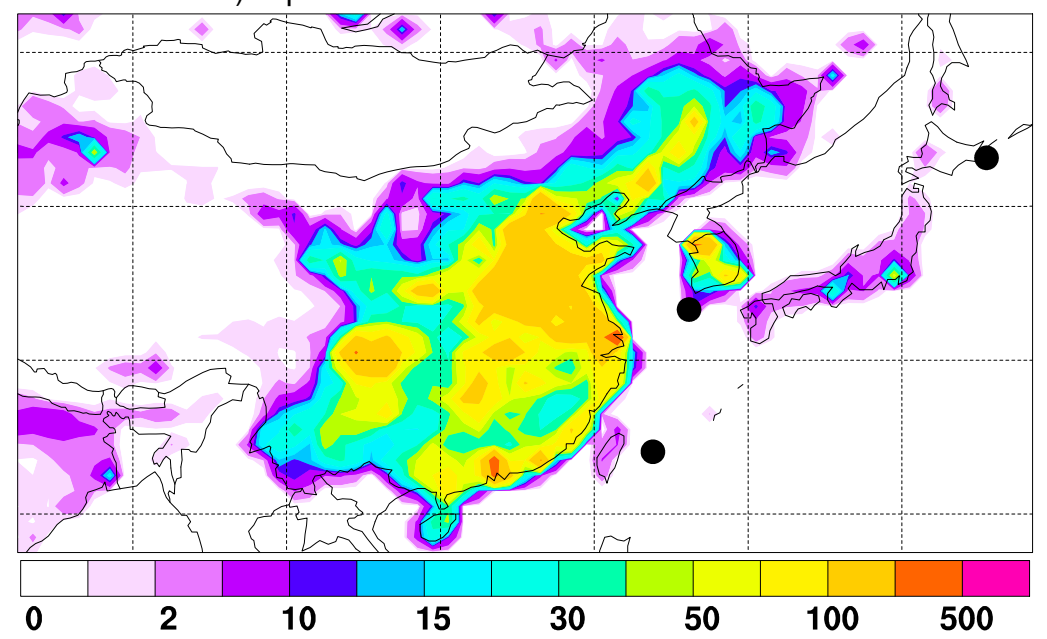

b) A posteriori emissions

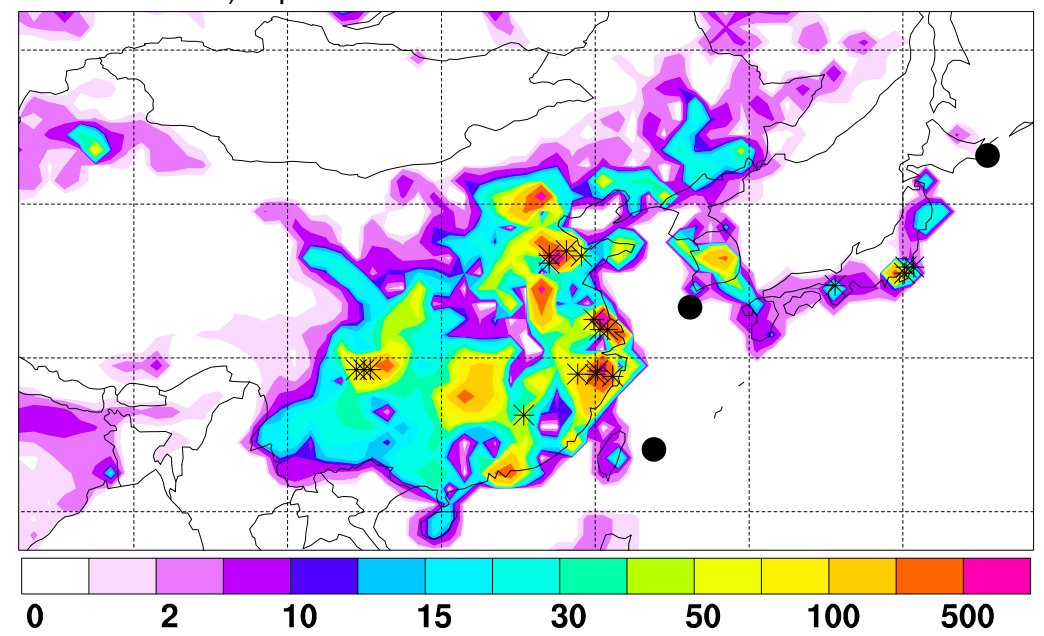

c) A posteriori minus a priori emissions

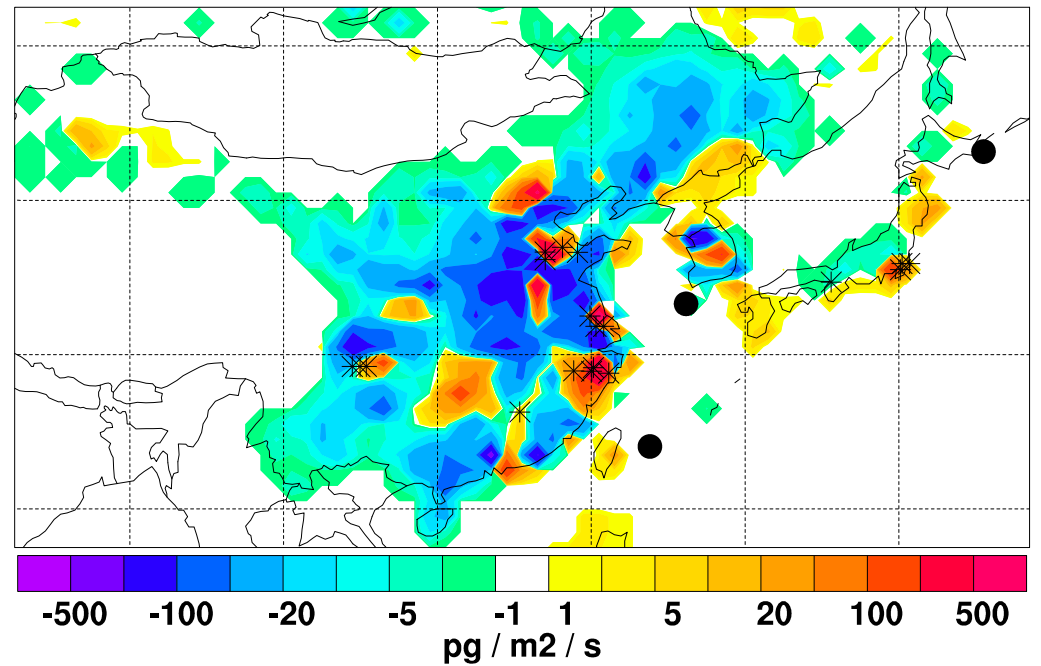

Fig. 4. Maps of the a priori (a), a posteriori (b), and difference between a posteriori and a priori (c) HFC-23 emissions for the year 2008. Black dots indicate the location of measurement stations, asterisks in panels (b) and (c) mark the locations of Chinese and Japanese factories known to have produced HCFC-22 in the year 2008. 
Table 4. HCFC-22 emissions (kt/yr) per country/region for the year 2008. $\mathrm{B}_{a}$ and $\mathrm{B}_{b}$ are our best estimate a priori and a posteriori emissions, respectively; $\mathrm{M}_{a}$ and $\mathrm{M}_{b}$ are the mean a priori and a posteriori emissions from all inversions performed, and $\sigma_{a}$ and $\sigma_{b}$ are the corresponding standard deviations.

\begin{tabular}{lrrrr}
\hline Country/region & \multicolumn{1}{c}{$\mathrm{B}_{a}$} & \multicolumn{1}{c}{$\mathrm{M}_{a} \pm \sigma_{a}$} & \multicolumn{1}{c}{$\mathrm{B}_{b}$} & \multicolumn{1}{c}{$\mathrm{M}_{b} \pm \sigma_{b}$} \\
\hline China & 79.3 & $113.9 \pm 61.5$ & 65.3 & $68.1 \pm 6.6$ \\
Taiwan region & 3.0 & $2.7 \pm 1.2$ & 2.5 & $2.2 \pm 0.5$ \\
North Korea & 0.9 & $0.8 \pm 0.4$ & 2.1 & $2.2 \pm 0.3$ \\
South Korea & 21.1 & $18.7 \pm 8.3$ & 7.2 & $7.8 \pm 1.4$ \\
Japan & 7.6 & $6.7 \pm 3.0$ & 6.0 & $5.9 \pm 0.3$ \\
\hline
\end{tabular}

\subsection{National emission estimates}

\subsubsection{HCFC-22}

Table 4 provides HCFC-22 total emission estimates for several East Asian countries. Reported are both the a priori and the a posteriori emissions from the reference inversion $\left(\mathrm{B}_{a}\right.$ and $\mathrm{B}_{b}$ ) as well as the mean emissions from the 18 scenario inversions ( $\mathrm{M}_{a}$ and $\left.\mathrm{M}_{b}\right)$ and their corresponding standard deviations $\left(\sigma_{a}\right.$ and $\left.\sigma_{b}\right)$. For China, our best a posteriori estimate for the year 2008, $65 \mathrm{kt} / \mathrm{yr}$, is $18 \%$ lower than the bottom-up estimate of Wan et al. (2009) which was used for the reference case and which requires a relatively small adjustment to be consistent with the measurement data. The standard deviation of the a posteriori estimates, $\sigma_{b}=6 \mathrm{kt} / \mathrm{yr}$, is an order of magnitude smaller than the standard deviation of our a priori scenarios used for the inversions, $\sigma_{a}=61 \mathrm{kt} / \mathrm{yr}$. This shows that Chinese emissions are well constrained by the available measurement data. Our best estimate is larger than the estimate of Yokouchi et al. (2006), $52 \pm 34$ for the years 2004/2005 and falls between the 60 and $71 \mathrm{kt} / \mathrm{yr}$ reported by Stohl et al. (2009) for the years 2005 and 2006. Both the above studies were based on data from Hateruma, and using only Hateruma data for the year 2008 yields a Chinese emission of $77 \mathrm{kt} / \mathrm{yr}$ (see section 3.3). Thus, consistently using Hateruma data alone indeed reveals increasing Chinese HCFC-22 emissions but these results are biased high against our inversion using more input data. As discussed previously, the $165 \mathrm{kt} / \mathrm{yr}$ for the year 2007 reported by Vollmer et al. (2009) are certainly too high. Nevertheless, our a posteriori Chinese HCFC-22 emissions are a substantial fraction (17\%) of the global 2008 emissions of $375 \mathrm{kt} / \mathrm{yr}$ extrapolated from Montzka et al. (2009). The estimate is substantially lower than currently reported HCFC consumption in China (UNEP, 2009) which, assuming that HCFC-22 is the dominant HCFC consumed in China, suggests a considerable build-up of HCFC-22 banks and likely higher emissions in the future.

For the Taiwan region, the a posteriori best estimate is $2.5 \mathrm{kt} / \mathrm{yr}$, about half of the Taiwanese HCFC-22 consump-
Table 5. HCFC-141b emissions (kt/yr) per country/region for the year 2008 .

\begin{tabular}{lrrrr}
\hline Country/region & \multicolumn{1}{c}{$\mathrm{B}_{a}$} & \multicolumn{1}{c}{$\mathrm{M}_{a} \pm \sigma_{a}$} & \multicolumn{1}{c}{$\mathrm{B}_{b}$} & \multicolumn{1}{c}{$\mathrm{M}_{b} \pm \sigma_{b}$} \\
\hline China & 12.1 & $16.9 \pm 8.9$ & 12.1 & $12.1 \pm 1.6$ \\
Taiwan region & 1.0 & $0.9 \pm 0.4$ & 0.5 & $0.5 \pm 0.1$ \\
North Korea & 0.1 & $0.1 \pm 0.1$ & 0.6 & $0.6 \pm 0.1$ \\
South Korea & 3.1 & $2.7 \pm 1.2$ & 1.8 & $1.9 \pm 0.3$ \\
Japan & 1.1 & $1.0 \pm 0.4$ & 1.1 & $1.1 \pm 0.1$ \\
\hline
\end{tabular}

tion of $4.3 \mathrm{kt} / \mathrm{yr}$ in 2005 (Tsai and Chou, 2008). For North Korea, the inversion doubles the relatively low a priori emission, whereas for South Korea, it reduces the high a priori emissions by two thirds, resulting in best estimates of 2.1 and $7.2 \mathrm{kt} / \mathrm{yr}$, respectively. It is possible that the opposing trends in the neighboring countries are due to a "spill-over" of South Korean emissions into North Korea by the inversion. However, a strong reduction of the consumption-based a priori for South Korea is certainly real. Like for China, this suggests a substantial buildup of HCFC-22 banks in South Korea. For Japan, the inversion reduces the a priori emission by $21 \%$, resulting in an a posteriori emission of $6.0 \mathrm{kt} / \mathrm{yr}$ in the year 2008. This is a substantial decrease from $9.1 \mathrm{kt} / \mathrm{yr}$ for the year 2002 reported by Yokouchi et al. (2005) and from 8.9 (for 2005) and $7.3 \mathrm{kt} / \mathrm{yr}$ (for 2006) found by Stohl et al. (2009), confirming a successful phase-out of HCFC-22 in Japan.

\subsubsection{HCFC-141b}

HCFC-141b has been used as a foam-blowing agent and as a solvent for lubricants, coatings and cleaning fluids. For HCFC-141b, our inversion generally resulted in the smallest changes to the a priori emissions of all halocarbons considered in this study. There is nearly perfect agreement between the a priori and the a posteriori HCFC-141b emissions for China (Table 5), thus confirming the bottom-up estimate of Wan et al. (2009) which served as our reference case. Chinese HCFC-141b emissions are approximately $22 \%$ of the global total emission extrapolated from Montzka et al. (2009). The a posteriori emission patterns in China are somewhat different from those of HCFC-22, with relatively larger emissions in southern parts of China, particularly in Shanghai and the Pearl River Delta, and smaller emissions in Beijing.

For Japan, the inversion did not make an adjustment to the a priori estimate, even though this was based only on consumption data constrained by global emissions. In contrast, the national inventory (PRTR, 2009) reports emissions six times higher $(6.6 \mathrm{kt} / \mathrm{yr})$ which are inconsistent with our results. They are also inconsistent with recent aircraft measurements (Yokouchi, unpublished data) and, for that reason, were not used for our a priori estimate. It seems that 
Table 6. HCFC-142b emissions (kt/yr) per country/region for the year 2008 .

\begin{tabular}{llcll}
\hline Country/region & $\mathrm{B}_{a}$ & $\mathrm{M}_{a} \pm \sigma_{a}$ & $\mathrm{~B}_{b}$ & $\mathrm{M}_{b} \pm \sigma_{b}$ \\
\hline China & 9.6 & $13.4 \pm 7.1$ & 7.3 & $7.7 \pm 0.7$ \\
Taiwan region & 0.08 & $0.07 \pm 0.03$ & 0.03 & $0.03 \pm 0.01$ \\
North Korea & 0.11 & $0.10 \pm 0.04$ & 0.20 & $0.20 \pm 0.06$ \\
South Korea & 2.4 & $2.2 \pm 1.0$ & 0.8 & $0.8 \pm 0.1$ \\
Japan & 0.7 & $0.7 \pm 0.3$ & 0.6 & $0.6 \pm 0.1$ \\
\hline
\end{tabular}

HCFC-141b emissions in Japan have dropped rapidly, since from aircraft measurements Yokouchi et al. (2005) derived an emission of $7.2 \mathrm{kt} / \mathrm{yr}$ for the year 2002 . This probably indicates shorter banking times than assumed in the PRTR (2009) emission inventory. The emissions in the Taiwan region were reduced by $50 \%$, down also by $50 \%$ from the last reported annual consumption of HCFC-141b for the year 2005 (Tsai and Chou, 2008), which guided our a priori estimate. According to Tsai and Chou (2008), HCFC-141b phase-out in the Taiwan region has already lead to a $50 \%$ consumption reduction between the years 2003 and 2005, so a further $50 \%$ reduction since 2005 is plausible. As for HCFC-22, the inversion strongly increased the emissions in North Korea but decreased them in South Korea. However, in the case of HCFC-141b the total for the two countries was reduced by only $25 \%$.

\subsubsection{HCFC-142b}

HCFC-142b is used as a blowing agent component for polyurethane foams and for extruded polystyrene foams. In all countries, the a posteriori emissions are smaller than the consumption-based a priori values (Table 6), except for North Korea, where the increase may actually be due to the "spill-over" of South Korean emissions. The Taiwan region appears to have near-zero emissions, in agreement with small emissions in 2005 and a rapid phase-out reported by Tsai and Chou (2008). Also for South Korea, the inversion reduces the a priori emissions by nearly a factor three, whereas the reductions for China and Japan are smaller. The Chinese a posteriori emissions of $7.3 \mathrm{kt} / \mathrm{yr}$ are $17 \%$ of the global total emission extrapolated from Montzka et al. (2009). Like for HCFC-22, this is less than the $10-18 \mathrm{kt} / \mathrm{yr}$ estimate of Vollmer et al. (2009) for the year 2007. The emission distribution within China is similar to that of HCFC-22.

\subsubsection{HFC-23}

China is the only country studied here with substantial HFC23 emissions (Table 7). The Chinese a posteriori emissions of $6.2 \mathrm{kt} / \mathrm{yr}$ are $27 \%$ lower than the EDGAR a priori emissions for the year 2005, 8.5 kt/yr (see also Fig. 4). They are also lower than the $10 \pm 4.6 \mathrm{kt} / \mathrm{yr}$ found by Yokouchi et al. (2006) for the years 2004/2005 based on Hateruma data.
Table 7. HFC-23 emissions (kt/yr) per country/region for the year 2008.

\begin{tabular}{lllll}
\hline Country/region & $\mathrm{B}_{a}$ & $\mathrm{M}_{a} \pm \sigma_{a}$ & $\mathrm{~B}_{b}$ & $\mathrm{M}_{b} \pm \sigma_{b}$ \\
\hline China & 8.5 & $8.5 \pm 3.5$ & 6.2 & $6.2 \pm 0.7$ \\
Taiwan region & 0.01 & $0.01 \pm 0.01$ & 0.03 & $0.02 \pm 0.01$ \\
North Korea & 0.01 & $0.01 \pm 0.01$ & 0.04 & $0.04 \pm 0.02$ \\
South Korea & 0.27 & $0.27 \pm 0.11$ & 0.19 & $0.21 \pm 0.05$ \\
Japan & 0.08 & $0.08 \pm 0.03$ & 0.21 & $0.20 \pm 0.03$ \\
\hline
\end{tabular}

Table 8. HFC-134a emissions (kt/yr) per country/region for the year 2008 .

\begin{tabular}{lcccc}
\hline Country/region & $\mathrm{B}_{a}$ & $\mathrm{M}_{a} \pm \sigma_{a}$ & $\mathrm{~B}_{b}$ & $\mathrm{M}_{b} \pm \sigma_{b}$ \\
\hline China & 20.4 & $16.3 \pm 8.2$ & 12.9 & $11.9 \pm 1.7$ \\
Taiwan region & 3.2 & $3.2 \pm 1.3$ & 0.8 & $0.8 \pm 0.2$ \\
North Korea & 0.17 & $0.19 \pm 0.08$ & 0.46 & $0.47 \pm 0.10$ \\
South Korea & 0.35 & $0.40 \pm 0.18$ & 1.9 & $1.8 \pm 0.3$ \\
Japan & 3.0 & $3.0 \pm 1.2$ & 3.1 & $3.1 \pm 0.2$ \\
\hline
\end{tabular}

This may reflect a real decrease of emissions in recent years, since several Clean Development Mechanism projects aimed at reducing HFC-23 emissions during HCFC-22 production in China, and this may have more than compensated the increase in HCFC-22 production. Still, these numbers mean that China accounts for more than $50 \%$ of the global HFC23 emissions. Our a posteriori HFC-23 emissions for Japan, $0.21 \mathrm{kt} / \mathrm{yr}$, are nearly three times higher than in the EDGAR inventory and more than an order of magnitude higher than the $19 \mathrm{t} / \mathrm{yr}$ listed in the GIO (2009) national inventory for 2007. They are, however, still a factor 30 smaller than the Chinese emissions.

\subsubsection{HFC-134a}

HFC-134a is mainly used as a refrigerant, especially in automobile air conditioners; it is also used as a propellant for extruded polystyrene foams. Japan reported HFC-134a emissions of $2.8 \mathrm{kt}$ in 2007 to UNFCCC, down from a maximum reported emission of $4.8 \mathrm{kt}$ in 2003 . Our inversion is consistent with the emission reports, resulting in emissions of $3.1 \mathrm{kt}$ for 2008 (Table 8), which is substantially lower than the $4.4 \mathrm{kt} / \mathrm{yr}$ reported by Yokouchi et al. (2005) for the year 2002 and the 5.3 and $4.0 \mathrm{kt} / \mathrm{yr}$ reported by Stohl et al. (2009) for the years 2005 and 2006, respectively. Thus, there is nearly perfect agreement in this case between bottom-up and topdown emission estimates. For China, HFC-134a emissions from automobile air conditioners were estimated at $7.3 \mathrm{kt} / \mathrm{yr}$ in 2005 and $21.2 \mathrm{kt} / \mathrm{yr}$ in 2010 (Hu et al., 2009). We have used an a priori value of $20.3 \mathrm{kt} / \mathrm{yr}$, since we expect that automobile air conditioners account for only two thirds of total HFC-134a emissions. Our reference a posteriori emission is 
substantially lower, $12.9 \mathrm{kt} / \mathrm{yr}$, indicating that the growth of automobile air conditioner emissions may have been overestimated by $\mathrm{Hu}$ et al. (2009) and/or that other sources contribute less than expected. The Chinese emission is about $9 \%$ of the global HFC-134a emissions based on Velders et al. (2009), a smaller fraction than for the HCFCs. However, a comparison with estimates based on Hateruma data from Yokouchi et al. (2006) for the year 2004/2005 (3.9 kt/yr) and from Stohl et al. (2009) for the years $2005(9.8 \mathrm{kt} / \mathrm{yr})$ and $2006(11.9 \mathrm{kt} / \mathrm{yr})$ reveals a strong growth of Chinese HFC134a emissions.

For the Taiwan region, the a posteriori emissions are more than a factor three lower than the extrapolated potential emissions from Tsai (2006). Either HFC-134a imports to the Taiwan region dropped considerably since 2004, or only a fraction of the imported HFC-134a is actually emitted in the Taiwan region. In contrast, emissions in South Korea are increased by more than a factor of five by the inversion (even more if some of the increase for North Korea is actually due to South Korean emissions), indicating that our populationbased a priori emissions were much too low.

\subsubsection{HFC-152a}

HFC-152a is used as a propellant for specialised industrial aerosols and as a blowing agent component for extruded polystyrene foams. For Japan, the inversion reduced the a priori HFC-152a emission (an extrapolation of the 2007 emission reported to UNFCCC) by nearly a factor of two (Table 9), to $0.9 \mathrm{kt} / \mathrm{yr}$. This value is higher than the $0.26 \mathrm{kt} / \mathrm{yr}$ reported for the year 2002 (Yokouchi et al., 2005) but smaller than the 1.5 and $1.3 \mathrm{kt} / \mathrm{yr}$ estimated for the years 2005 and 2006, respectively (Stohl et al., 2009). The Chinese a posteriori emission, $3.4 \mathrm{kt} / \mathrm{yr}$, is approximately $7 \%$ of the global HFC-152a emissions, the smallest fraction of all studied substances. This value is smaller than the surprisingly high estimate of $4.3 \mathrm{kt} / \mathrm{yr}$ for the year 2002 from Yokouchi et al. (2006) but similar to the estimates from Stohl et al. (2009) for 2005 and 2006. The inversion reduced the Taiwanese a priori emissions by more than an order of magnitude, suggesting that there are no substantial HFC-152a emissions in the Taiwan region, which agrees with a reported low HFC152a consumption in the Taiwan region of only $5 \mathrm{t}$ in 2004 (Tsai, 2006). Also North and South Korea have small emissions of HFC-152a.

\section{Conclusions}

We have used an inversion method based on atmospheric measurement data, bottom-up emission information and an atmospheric transport model to improve regional estimates for East Asia for the year 2008 of the emissions of three hydrochlorofluorocarbons (HCFC-22, HCFC-141b, HCFC142b) and three hydrofluorocarbons (HFC-23, HFC-134a,
Table 9. HFC-152a emissions (kt/yr) per country/region for the year 2008 .

\begin{tabular}{lllll}
\hline Country/region & $\mathrm{B}_{a}$ & $\mathrm{M}_{a} \pm \sigma_{a}$ & $\mathrm{~B}_{b}$ & $\mathrm{M}_{b} \pm \sigma_{b}$ \\
\hline China & 4.0 & $6.2 \pm 3.6$ & 3.4 & $3.8 \pm 0.5$ \\
Taiwan region & 0.17 & $0.16 \pm 0.07$ & 0.02 & $0.02 \pm 0.02$ \\
North Korea & 0.17 & $0.16 \pm 0.07$ & 0.15 & $0.13 \pm 0.02$ \\
South Korea & 0.36 & $0.34 \pm 0.14$ & 0.19 & $0.21 \pm 0.04$ \\
Japan & 1.6 & $1.6 \pm 0.7$ & 0.9 & $0.8 \pm 0.1$ \\
\hline
\end{tabular}

HFC-152a). The halocarbon measurements are from two sites in Japan (Cape Ochi-ishi and Hateruma), a site in South Korea (Gosan) and a site in China (Shangdianzi), as well as from stations in Europe and North America. The bottomup a priori emission information was constructed by merging data from specific national studies for China, Japan and the Taiwan region, national HCFC consumption reports to UNEP, national HFC emission reports to UNFCCC, information on global emissions and a population database. Twentyday backward model simulations were made from every station every three hours with the Lagrangian particle dispersion model FLEXPART. The inversion optimized the agreement between the model results and the measurements by adjusting the gridded emissions while also taking into account the a priori emission information and uncertainties in the modelmeasurement comparison as well as the a priori emissions. Our main conclusions from this study are as follows:

- The results of the model calculations are generally well correlated with the halocarbon measurements. For instance, for HCFC-22 the model explains 19-63\% (26$70 \%$ ) of the variance of the measurements at the different stations when using the a priori (a posteriori) emissions.

- The a posteriori country total emissions were remarkably robust against changes of the a priori emission information as well as against the removal of data from a single station. Results obtained from inversions done with data from single stations are, however, more variable. Using data from a single station, the inversion can confuse contributions from emissions located in the same direction but at shorter and longer distances from the station. Often, small emissions from close-by sources can have a similar effect on the measurements as larger emissions from sources further away. This demonstrates the synergistic value of multiple-station inversions where emission regions are "observed" by the stations from different viewing angles. This effect also explains why a previous inversion study (Vollmer et al., 2009) using data only from the Shangdianzi station arrived at much higher annual emissions of HCFC-22 and HCFC-142b from China than we obtained here. 
- HFC-23 is emitted mainly from large mostly known point sources as a by-product during manufacture of HCFC-22, especially in China. Contrary, the a priori emission information taken in this case from the EDGAR data set is very smooth and follows the population distribution. Nevertheless, the inversion was capable of sharply increasing the emissions in all regions where clusters of HCFC-22 factories are located but it mostly decreased emissions elsewhere. The successful identification of the point sources serves as a validation of our inversion method. Overall, Chinese HFC-23 emissions $(6.2 \pm 0.7 \mathrm{kt} / \mathrm{yr})$ are some $30 \%$ smaller than in the EDGAR inventory for the year 2005. This may indicate that recent Clean Development Mechanism projects in China targeted towards reducing HFC-23 emissions from HCFC-22 production more than compensated the growing HCFC-22 production. Nevertheless, China still contributes more than $50 \%$ of the global HFC-23 emissions.

- Total emissions in the year 2008 for China, the Taiwan region, North Korea, South Korea and Japan are reported in Tables 3-8. Caution should be paid when interpreting these results that the reported uncertainties do not account for systematic errors and, thus, are lower estimates of true uncertainties. For small countries, attribution of emissions can be difficult if a large fraction of the emissions occurs along the country boundaries. This is the case especially for South Korea and North Korea, where it is likely that in the inversion emissions from South Korea "spill over" into North Korea.

- In many cases where good bottom-up data are available, the a posteriori estimates are quite similar to the a priori values. For instance, there is nearly perfect agreement of our a posteriori results with the HCFC-141b emission estimate for China by Wan et al. (2009) and our HCFC-22 estimate is only $18 \%$ lower than theirs. Also for Japan, there is generally good agreement. However, a national inventory (not used for defining our a priori emissions) for 2007 reports Japanese HCFC-141b emissions that are a factor 6 higher than our best estimate, whereas another national inventory (GIO, 2009) has more than a factor 10 lower HFC-23 emissions than our best estimate.

- Where no bottom-up emission information is available and our a priori values are based on consumption data or global population distribution, the inversion algorithm often makes very strong adjustments. For instance, for South Korea consumption-based a priori values are reduced substantially by the inversion, e.g., by two thirds for HCFC-22, suggesting the build-up of HCFC-22 in banks. The fact that our a posteriori emissions mostly are smaller than current consumption values in East Asian countries suggests a substantial build-up of halo- carbon banks. Another factor may be that halocarboncontaining goods are exported from the region, so that emissions take place somewhere else.

- The largest change between a priori and a posteriori, more than a factor 10 reduction, occurred for HFC-152a for the Taiwan region. The negligible Taiwanese emissions actually fit with a reported HFC-152a consumption of only $5 \mathrm{t}$ in 2004 (Tsai, 2006).

- China's HCFC and HFC emissions are a substantial fraction of global emissions. Our best estimates of Chinese emissions for the year 2008 are $65.3 \pm 6.6 \mathrm{kt} / \mathrm{yr}$ for HCFC-22 (17\% of global emissions), $12.1 \pm 1.6 \mathrm{kt} / \mathrm{yr}$ for HCFC- $141 \mathrm{~b}(22 \%), 7.3 \pm 0.7 \mathrm{kt} / \mathrm{yr}$ for HCFC-142b (17\%), 12.9 $\pm 1.7 \mathrm{kt} / \mathrm{yr}$ for HFC-134a (9\%) and $3.4 \pm 0.5 \mathrm{kt} / \mathrm{yr}$ for HFC-152a (7\%). Given the substantial recent growth of the consumption of these substances and emission delays due to banking, the Chinese emissions are bound to increase and constitute a growing fraction of the global emissions during the next few years.

Acknowledgements. R. G. Prinn as well as the whole AGAGE team are acknowledged for access to data. Met.no and ECMWF provided access to ECMWF data, and we acknowledge use of EDGAR emission data. This is a pre-study for the project SOGG-EA (Sources of Greenhouse Gases in East Asia), which is partly funded by the Norwegian Research Council. Observations at Hateruma Island and Ochiishi were supported by the Global Environment Fund (Ministry of the Environment of Japan). Measurements at Gosan were funded by the Korea Meteorological Administration Research and Development Program under Grant CATER 2009-4109. Measurements at Shangdianzi were funded by the Sino-Swiss Science and Technology Cooperation Joint Research Projects 2SMONG and by the Chinese projects 2007DFA20650 International S\&T Cooperation Program of MOST and GYHY200806026 National Non-profit Research Project to Serve the Public Interest.

Edited by: F. Dentener

\section{References}

Ashford, P., Clodic, D., McCulloch, A., and Kuijpers, L.: Emission profiles from the foam and refrigeration sectors comparison with atmospheric concentrations. Part 2: Results and discussion, Intern. J. Refrigeration, 27, 701-716, 2004.

Barletta, B., Meinardi, S., Simpson, I. J., Rowland, F. S., Chan, C.Y., et al.: Ambient halocarbon mixing ratios in 45 Chinese cities, Atmos. Environ., 40, 7706-7719, 2006.

Blake N. J. Blake, D. R., Simpson, I. J., Meinardi, S., Swanson, A. L., et al.: NMHCs and halocarbons in Asian continental outflow during the Transport and Chemical Evolution over the Pacific (TRACE-P) Field Campaign: Comparison With PEM-West B, J. Geophys. Res., 108, 8806, doi:10.1029/2002JD003367, 2003.

Chan, C. Y., Tang, J. H., Li, Y. S., and Chan, L. Y.: Mixing ratios and sources of halocarbons in urban, semi-urban and rural 
sites of the Pearl River Delta, South China, Atmos. Environ., 40, 7331-7345, 2006.

Center for International Earth Science Information Network (CIESIN): Gridded Population of the World: Future Estimates, Socioeconomic Data and Applications Center (SEDAC), Columbia University, Palisades, NY, USA,available online at: http://sedac.ciesin.columbia.edu/gpw (downloaded on 22 April 2008), 2005.

Dunse, B., Steele, P., Wilson, S., Fraser, P., and Krummel, P.: Trace gas emissions from Melbourne Australia, based on AGAGE observations at Cape Grim, Tasmania, 1995-2000, Atmos. Environ., 39, 6334-6344, 2005.

European Commission, Joint Research Centre (JRC)/Netherlands Environmental Assessment Agency (PBL): Emission Database for Global Atmospheric Research (EDGAR), release version 4.0, available from http://edgar.jrc.ec.europa.eu, 2009.

Eckhardt, S., Prata, A. J., Seibert, P., Stebel, K., and Stohl, A.: Estimation of the vertical profile of sulfur dioxide injection into the atmosphere by a volcanic eruption using satellite column measurements and inverse transport modeling, Atmos. Chem. Phys., 8, 3881-3897, 2008,

http://www.atmos-chem-phys.net/8/3881/2008/.

Greenhouse Gas Inventory Office of Japan (GIO): National Greenhouse Gas Inventory Report of JAPAN, Ministry of the Environment, Japan, 2009.

Guo, H., Ding, A. J., Wang, T., Simpson, I. J., Blake, et al.: Source origins, modeled profiles, and apportionments of halogenated hydrocarbons in the greater Pearl River Delta region, southern China, J. Geophys. Res., 114, D11302, doi:10.1029/2008JD010360, 2009.

Hartley, D. and Prinn, R.: Feasibility of determining surface emissions of trace gases using an inverse method in a threedimensional chemical transport model, J. Geophys. Res., 98, 5183-5197, 1993.

Hu, J., Wan, D., Li, C., Zhang, J., and Yi, X.: Forecasting of consumption and emission of HFC-134a used in automobile air conditioner sector in China, Adv. Clim. Change Res., 5, 1-6, (in Chinese), 2009.

Kim, J., Li, S., Kim, K.-R. Stohl, A., Mühle, J. M., et al.: Regional atmospheric emissions determined from measurements at Jeju Island: Halogenated compounds from China, submitted, Geophys. Res. Lett., 2010.

Manning, A. J., Ryall, D. B., Derwent, R. G., Simmonds, P. G., and O'Doherty, S.: Estimating European emissions of ozonedepleting and greenhouse gases using observations and a modeling back-attribution technique, J. Geophys. Res., 108, 4405, doi:10.1029/2002JD002312, 2003.

McCulloch, A., Midgley, P. M., and Ashford, P.: Releases of refrigerant gases (CFC-12, HCFC-22 and HFC-134a) to the atmosphere, Atmos. Environ., 37, 889-902, 2003.

McCulloch, A., Midgley, P. M., and Lindley, A. A.: Recent changes in the production and global atmospheric emissions of chlorodifluoromethane (HCFC-22), Atmos. Environ., 40, 936-942, 2006.

McCulloch, A., Lindley, A. A.: Global emissions of HFC-23 estimated to the year 2015, Atmos. Environ., 41, 1560-1566, 2007.

Miller, B. R., Weiss, R. F., Salameh, P. K., Tanhua, T., Greally, B. R., Mühle, J., and Simmonds, P. G.: Medusa: A sample preconcentration and GC/MS detector system for in situ measurements of atmospheric trace halocarbons, hydrocarbons, and sulfur com- pounds, Anal. Chem., 80, 1536-1545, 2008.

Millet, D. B., Atlas, E. L., Blake, D. R., Blake, N. J., Diskin, G. S., et al. (2009): Halocarbon emissions from the United States and Mexico and their Global Warming Potential, Environ. Sci. Technol., 43, 1055-1060, 2009.

Molina, M., Zaelke, D., Sarma, K. M., Andersen, S. O., Ramanathan, V., and Kaniaru, D. (2009): Reducing abrupt climate change risk using the Montreal Protocol and other regulatory actions to complement cuts in $\mathrm{CO}_{2}$ emissions, Proc. Natl. Acad. Sci. USA, Early Edition, http://www.pnas.org/content/ early/2009/10/09/0902568106.full.pdf, 2009.

Montzka, S. A., Hall, B. D., and Elkins, J. W.: Accelerated increases observed for hydrochlorofluorocarbons since 2004 in the global atmosphere, Geophys. Res. Lett., 36, L03804, doi:10.129/2008GL036475, 2009.

Montzka, S. A., Kuijpers, L., Battle, M. O., Aydin, M., Verhulst, K., Saltzman, E. S., and Fahey, D. W.: Recent increases in global HFC-23 emissions, Geophys. Res. Lett., 37, L02808, doi:10.1029/2009GL041195, 2010.

O’Doherty, S., Cunnold, D. M., Manning, A., Miller, B. R., Wang, R. H. J., et al.: Rapid growth of hydrofluorocarbon 134a and hydrochlorofluorocarbons 141b, 142b, and 22 from Advanced Global Atmospheric Gases Experiment (AGAGE) observations at Cape Grim, Tasmania, and Mace Head, Ireland, J. Geophys. Res., 109, D06310, doi:10.1029/2003JD004277, 2004.

O’Doherty, S., Cunnold, D. M., Miller, B. R., Mühle, J., McCulloch, A., et al.: Global and regional emissions of HFC-125 $\left(\mathrm{CHF}_{2} \mathrm{CF}_{3}\right)$ from in situ and air archive atmospheric observations at AGAGE and SOGE observatories, J. Geophys. Res., 114, D23304, doi:10.1029/2009JD012184.

Palmer, P. I., Jacob, D. J., Mickley, L. J., Blake, D. R., Sachse, G. W., et al.: Eastern Asian emissions of anthropogenic halocarbons deduced from aircraft concentration data, J. Geophys. Res., 108, 4753, doi:10.1029/2003JD003591, 2003.

Prinn, R. G., Weiss, R. F., Fraser, P. J., Simmonds, P. G., Cunnold, D. M., et al: A history of chemically and radiatively important gases in air deduced from ALE/GAGE/AGAGE, J. Geophys Res., 105, 17751-17792, 2000.

PRTR: Pollutant Release and Transfer Register Data, FY 2007, Ministry of Economy, Trade and Industry, and Ministry of the Environment (in Japanese), 2009.

Seibert, P.: Inverse modelling of sulfur emissions in Europe based on trajectories, In: Inverse Methods in Global Biogeochemical Cycles, edited by :Kasibhatla, P., Heimann, M., Rayner, P., Mahowald, N., Prinn, R. G., and Hartley, D. E., Geophysical Monograph 114, American Geophysical Union, ISBN: 0-87590-097-6, 147-154, 2000.

Stohl, A., Hittenberger, M., and Wotawa, G.: Validation of the Lagrangian particle dispersion model FLEXPART against large scale tracer experiment data, Atmos. Environ., 32, 4245-4264, 1998.

Stohl, A., Forster, C., Frank, A., Seibert, P., and Wotawa, G.: Technical note: The Lagrangian particle dispersion model FLEXPART version 6.2., Atmos. Chem. Phys., 5, 2461-2474, 2005, http://www.atmos-chem-phys.net/5/2461/2005/.

Stohl, A., Seibert, P., Arduini, J., Eckhardt, S., Fraser, P., et al.: An analytical inversion method for determining regional and global emissions of greenhouse gases: Sensitivity studies and application to halocarbons, Atmos. Chem. Phys., 9, 1597-1620, 2009, 
http://www.atmos-chem-phys.net/9/1597/2009/.

Tsai, W. T.: Energy and environmental policies relating to hydrofluorocarbons (HFCs) emissions mitigation and energy conservation in Taiwan, Energy Conversion and Management, 47, 23082318, 2006.

Tsai, W. T. and Chou, Y.-H.: Governmental policies on hydrochlorofluorocarbons (HCFCs) mitigation and its cleaner production measures - case study in Taiwan, J. Cleaner Production, 16, 646654, 2008.

United Nations Environment Programme (UNEP): Ozone Secretariat Data Access Centre, http://ozone.unep.org/ Data_Reporting/Data_Access/, UNEP, Nairobi, Kenya, accessed on 26 September 2009, 2009.

Velders, G. J. M., Fahey, D. W., Daniel, J. S., McFarland, M., and Andersen, S. O.: The large contribution of projected HFC emissions to future climate forcing, Proc. Natl. Acad. Soc., 106, 10949-10954, 2009.
Vollmer, M. K., Zhou, L. X., Greally, B. R., Henne, S., Yao, B., et al:: Emissions of ozone-depleting halocarbons from China, Geophys. Res. Lett., 36, L15823, doi:10.1029/2009GL038659, 2009.

Wan, D., Xu, J., Zhang, J., Tong, X., and Hu, J.: Historical and projected emissions of major halocarbons in China, Atmos. Environ., 43, 5822-5829, 2009.

Yokouchi, Y., Inagaki, T., Yazawa, K., Tamaru, T., Enomoto, T., and Izumi, K.: Estimates of ratios of anthropogenic halocarbon emissions from Japan based on aircraft monitoring over Sagami Bay, Japan, J. Geophys. Res., 110, D06301, doi:10.1029/2004JD005320, 2005.

Yokouchi, Y., Taguchi, S., Saito, T., Tohjima, Y., Tanimoto, H., and Mukai, H.: High-frequency measurements of HFCs at a remote site in east Asia and their implications for Chinese emissions, Geophys. Res. Lett., 33, L21814, doi:10.1029/2006GL026403, 2006. 